\title{
Comparison Between Uses of Antibiotics as Opposed to no Antibiotics in Clean Episiotomy
}

\author{
Rabia Akram¹, Tahira Fatima², Arifa Zafar, Bushra Haq ${ }^{4}$, Sidra Afzal ${ }^{5}$, Saba Iqbal ${ }^{6}$ \\ ${ }^{1}$ Assistant Professor, Department of Gynea \& Obst, Shalamar Institute of Health Sciences, Lahore, ${ }^{2}$ Assistant Professor, \\ Department of Gynea \& Obst, Shalamar Institute of Health Sciences, Lahore, ${ }^{3}$ Assistant Professor, Department of Gynea \& \\ Obst, Pak Rad Crescent Medical \& Dental College, Lahore, ${ }^{4}$ Senior Registrar Department of Gynea \& Obst, Services Hospital, \\ Lahore, ${ }^{5}$ Assistant Professor, Department of Gynea \& Obst, Pak Rad Crescent Medical \& Dental College, Lahore, ${ }^{6}$ Director \\ Medical Education, Pak Rad Crescent Medical \& Dental College, Lahore, Punjab, Pakistan
}

Corresponding author: Dr Saba Iqbal, House \#002 Block A, Dream Avenue Raiwind Road, Lahore, Punjab, Pakistan

DOI: http://dx.doi.org/10.21276/ijcmsr.2019.4.4.40

How to cite this article: Rabia Akram, Tahira Fatima, Arifa Zafar, Bushra Haq, Sidra Afzal, Saba Iqbal. Comparison between uses of antibiotics as opposed to no antibiotics in clean episiotomy. International Journal of Contemporary Medicine Surgery and Radiology. 2019;4(4):D168-D171.

\section{A B S T R A C T}

Introduction: An episiotomy is a surgical incision of the perineum, made to increase the diameter of introitus during child birth. Current study aimed to compare the outcome of clean episiotomy with and without postoperative antibiotic cover.

Material and methods: A Randomized control was done in the department of gynecology and obstetrics, combined military hospital Lahore, over a period of six months form 12-05-2009 to 11-11-2009. Total 1000 cases were included in this study (five hundred cases in each group). Mediolateral episiotomy was given to all the patients, interrupted stitches of absorbable suture i.e catgut number, zero applied to all patients.

Results: Mean age was $27.4 \pm 4.3$ with antibiotics. In group A (with antibiotics) 6 patients (1.2\%) get infected and 494 patients (98.8\%) remained healthy. In group B (without antibiotics) 12 Patients (2.4\%) get infected and remaining 488 (97-6\%). The complication of episiotomy infection, bruising, swelling, bleeding, extended healing time, haematoma formation, painful scar which may require period remained healthy. In group A, out of the $6(1.2 \%)$ infected case, $4(0.8 \%)$ women were presented with discharge and pus from the wound and 2 patients $(0.4 \%)$ with gaped wound. While in group B, out of $12(2.4 \%)$ cases, 7 women (1.4\%) were having discharge/pus coming out of the wound and 5 patients (1.0\%) were having gaped wound.

Conclusion: Short term antimicrobial prophylaxis regimen does not possess significant role in preventing clean surgical wound infection role working condition in respect to environment, i.e standard of labour suite, operation theater, expertise and aseptic measures should be improved to achieve better results

Keywords: Episiotomy, Preoperative, Postoperative, Antibiotic, Absorbable Suture

\section{INTRODUCTION}

Episiotomy is indicated in multiple clinical situations like, CTG shows Absence of acceleration means fetus having bradycardia, Shoulder Dystocia, Breech Delivery or good size baby. ${ }^{1}$ It is also indicated to reduce duration of second stage. The world Health Organization recommends an episiotomy rate of the $10 \%$ for normal deliveries. ${ }^{2,3,4}$ It is an intentional second degree principle incision but it is not third degree tears. It is the most commonly performed obstetric procedure.

There are three type of episiotomy i.e midline, lateral and mediolateral episiotomy. Midline is more common in USA ${ }^{1}$, mediolateral episiotomy is standard in UK but still do not know which type of episiotomy is better. ${ }^{5}$ Episiotomy should be selectively performed and recommended with appropriate indication. ${ }^{1}$ Like where perineal trauma of abstinence from sexual inter course and future problems with incontinence. Therefore, oral anti biotics can be used in selected cases having preexisting infection or for postoperative complications. ${ }^{5,6,7}$
The rates of episiotomies decreased dramatically worldwide, In USA from $69.3 \%$ in 1983 to $19.4 \%$ in 2000 . While in UK from $19.1 \%$ in 2000 to $15.1 \%$ in $2012 .{ }^{8}$

The rational of my study is that routine antibiotics prophylaxis does not significantly reduce the incidence of postoperative wound infections in clean procedure. ${ }^{9}$ This study will be beneficial to conclude that by minimizing routine use of prophylactic antibiotics, we can reduce the cost, toxicity, side effects and the resistance to drugs which have been misused in our clinical practices.

\section{MATERIAL AND METHODS}

This was randomized control trial conducted at department of obstetrics and Gynecology, Combined Military Hospital Lahore from $12^{\text {th }}$ Feb 2009 to $11^{\text {th }}$ Aug 2009.

\section{Inclusion criteria}

The patients undergoing episiotomy were age between 20-35 years and of any parity with gestational age between 37-41 weeks. Patients were afebrile with $\mathrm{Hb}$ level > 10gm / dl and 
BMI between 20-30. They were having intact membranes in the latent phase of labour. (Confirmed by the history and pelvic examination).

\section{Exclusion criteria}

The patients were excluded in the study who were allergic to amoxicillin and clavulanic acid, who were having pelvic or systemic infection, Chorioamnionities, difficult labour and delivery (like instrumental delivery prolonged labour, obstructed labour, vaginal and cervical tears, manual removal of placenta, postnatal uterine exploration, diabetes mellitus, pregnancy induced hypertension and chronic illness.

All patients coming to labour room for delivery, either booked or un-booked, were enrolled. Demographic history was recorded. After taking oral informed consent of episiotomy, the selected patients were randomized into two groups by using random number table. Mediolateral episiotomy was given to all the patients interrupted stitches of absorbable suture i.e cat gent no zero was applied to all the patients. Patients were divided into two group i.e A and B.

Tablet Augmentin 625mg (contain Amoxicillin and Clavulanic acid) was given orally to group $\mathrm{A}$ and no antibiotics were given to group B. Same instructions i.e hot bath, personal hygiene and to avoid constipation, were given to both the groups for episiotomy care. All patients were explained about one week follow up in O.P.D to look for outcome i.e presence or absence of wound infection. Data was analyzed using SPSS version 10.0 quantitative variable such as age was presented as mean and $\mathrm{SD}$. Qualitative variables such as discharge or pus (Yes/No), gaped wound (Yes/No) were presented as percentage and frequencies

These variables were presented as frequencies, to compare the presence or absence of infection between the two groups, chi-square was used and $\mathrm{P}$ value $<0.05$ was considered statistically significant with the confidence interval limits 95 percent. Instruments used in episiotomy were autoclaved to maintain the standard of sterilization.

\section{RESULT}

Majority of the women in both groups were between 20-
25 years, in group A 246 (49.2\%) patients, while in group B $262(52.4 \%)$ patients. While in group A 240(40.8\%) and in group B 193(38.6\%) were between 26 to 30 Years of age group. 50 patients from group $A$ and 55 patient form group $\mathrm{B}$ respectively, were from ages between 31 to 35 years. Mean age was $26.9 \pm 4.3$ with antibiotics patients and $26.9 \pm 4.1$ without antibiotics (table-1).

A group (with antibiotics) 6 patients (1.2\%) got infected and 494 patients $(98.8 \%)$ remained healthy. In group B, i.e without antibiotics, 12 patients (2.4\%) get infected and 488 (97.6\%) remained healthy (fig -1$)$.

In group A out of the 6(1.2\%) infected cases 4(0.8\%) women presented with discharge and pus from wound and 2 patients $(0.4 \%)$ presented with gapped wound. While in group B out of $12(2.4 \%)$ cases, 7 women (1.4) were having discharge / pus coming out of the wound and 5 patients (1.0\%) were having gaped wound (Table -2).

Table-1 shows the comparison between the two group i.e group A and group B. Among group A, 4(0.8\%) patients had discharge or pus from wound as compared to group B which had $0(1.4 \%)$ patients with pus. Among group A, 2(0.4\%) patients had gaped wound as compared to group B which had 05 (1.0) patients with gaped wound. In total group A (with antibiotics) were having infection in $6(1.2 \%)$ patients and from group B (without antibiotics) 12 (2.4\%) patients get infected. From group A 494 (98.8\%) patients remained healthy and from group B 488 (97.6\%) patients remained healthy.

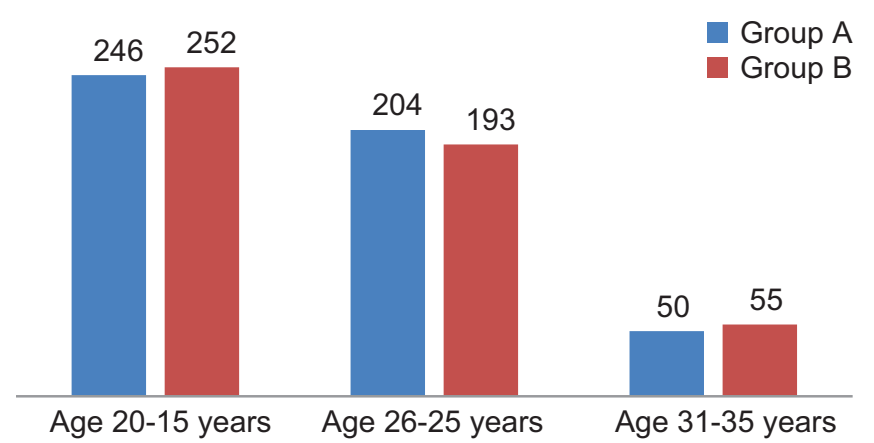

Figure-1: Distribution of cases by age

\begin{tabular}{|c|c|c|c|c|}
\hline \multirow[t]{2}{*}{ Type of Infection } & \multicolumn{2}{|c|}{ Group A (with antibiotics) } & \multicolumn{2}{|c|}{ Group B (without antibiotics) } \\
\hline & No & $\%$ & No & $\%$ \\
\hline Discharge /Pus & $4(n=1000)$ & 0.8 & 07 & 1.4 \\
\hline Gaped wound & $2(n=1000)$ & 0.4 & 05 & 1.0 \\
\hline Total & $6(n=1000)$ & 1.2 & 12 & 2.4 \\
\hline Healhy patients & $494(n=1000)$ & 98.8 & 488 & 97.6 \\
\hline \multicolumn{5}{|c|}{ Chi square $=0.12 ; \mathrm{df}=1 ; \mathrm{P}$ Valve $=0.732$ (Statistically in significant) } \\
\hline \multicolumn{5}{|c|}{ Table-1: Distribution of cases by type of infection at 1st week } \\
\hline
\end{tabular}

\begin{tabular}{|c|c|c|c|c|}
\hline \multirow[t]{2}{*}{ Infection } & \multicolumn{2}{|c|}{ Group A (with antibiotics) } & \multicolumn{2}{|c|}{ Group B (without antibiotics) } \\
\hline & No & $\%$ & No & $\%$ \\
\hline Yes & 06 & 1.2 & 12 & 2.4 \\
\hline No & 494 & 98.8 & 488 & 97.6 \\
\hline Total & 500 & 100.0 & 500 & 100.0 \\
\hline \multicolumn{5}{|c|}{ Chi square $=2.04 ; \mathrm{df}=0.1 ; \mathrm{P}$ Valve $=0.153$ (Statistically in significant } \\
\hline & Tabl & ases by & D00) & \\
\hline
\end{tabular}




\section{DISCUSSION}

The rate of episiotomy in the department should be $10 \%$ and selective episiotomy should be performed with appropriate indications and complications should be kept in mind which will significantly reduce the need of antibiotics and their unnecessary usage for threat of getting nosocomial information, thus reducing the hospital burden and cost. ${ }^{10}$

Nosocomial infections are by far the most common complication affecting the hospitalized patients. Among these, surgical site infections (SSIs) constitute the second most common category of adverse event, approximately $20 \%$ of all nosocomial infections and rank third respect to cost. Prevention of SSIs requires aggressive efforts to modify the physicians behavior and to implement system based changes aimed at eliminating indiscriminate and or inappropriate usage of antibiotics. ${ }^{11}$ Over consumption of antibiotics in teaching hospital should be controlled and intervention consisting of updating consensus guidelines and education training resulted in significant improvement of prescribing antibiotics in department of gynae and obstetrics and sustainability of the improvements needs to be explored. ${ }^{12}$

In present study, patients who received oral antibiotics in clean episiotomy had only $1.2 \%$ infection rate and those not receiving oral antibiotics has $2.4 \%$ infection rate which is comparable with other studies that show statistically insignificant difference. ${ }^{13}$ Current study has also proved that short term antimicrobial prophylaxis regime do not possess significantly marked role in preventing clean surgical wound infection, which is comparable with other studies.

The Scottish inter collegiate guidelines network (SIGN) publication 35 on antibiotic prophylaxis in surgery includes the goals of surgical prophylaxis that are to reduce the incidence of surgical site infections (SSIs) use of antibiotics in a manner that if supported by evidence of effectiveness minimize the effects of antibiotics in the patients normal flora, minimize adverse effects and cause minimal changes to the host defaces. ${ }^{14,15}$

Present study also proved that continuation of prophylactic antibiotics in postoperative period in considered to be unnecessary in clean surgical wounds which in comparable with study of Parveen-et al. ${ }^{16}$ According to Calder dale and Hudder's filed NHS foundation trust antibiotic guideline (2007), it states that antibiotics prophylaxis in surgeries is necessary because it is related to the consequences of SSI, reduction in short - term morbidity, reduces long and short terms postoperative mortality and reduction in duration of hospital stay. But the risks of prophylaxis are that it increases antimicrobial antibiotic resistance, clostridium difficle associated colitis (single antibiotics dose increases risk of carriage) and anaphylaxis. ${ }^{12}$

International classification of operations of their risk of infection defining clean wound, clean contaminated wounds, contaminated and dirty wound showed that the risk of getting infection without antibiotics in clean our study that shows $2.4 \%$ infection rate. ${ }^{17,18}$ Although the general principles of surgical prophylaxis have been quite clearly defined in last few decades. Advances in surgical techniques, the changes in bacterial ecology in hospital, the bacterial resistance and the substantial increase in the surgical population at risk suggest that several aspect of surgical prophylaxis in clean wounds should be review and new controlled studies should be carried out. ${ }^{18}$

Although the general principles of surgical prophylaxis have been quite clearly defined during the last few decades, advances in surgical techniques, the changes in bacterial ecology in hospital, the bacterial resistance and the substantial increase in the surgical population at risk suggest that several aspect of surgical prophylaxis in clean wounds should be reviewed and new controlled studies should be carried out. ${ }^{19}$ The traditional surgical classification scheme needs to be replaced with a classification that additionally accounts for patients specific risk factors. ${ }^{20}$ The limitations of the current scheme may party explain why current guidelines are so seldom followed in clinical practice. Framing of antibiotics use guidelines are required. ${ }^{21}$

Thus in short in our study, we have taken group A which were given antibiotics after episiotomy and group B which were not given antibiotics and infection in the second group was not significant according to $\mathrm{P}$ valves.

\section{CONCLUSION}

Results of the present study indicate that antibiotics have minimal role in the absence of risk factors as shown in comparison between group A and group B. The role of antibiotics cannot be denied in controlling infection rates in selective patients who have risk factors. In clean episiotomy, use of antibiotics can create an over burden regarding cost, side effects and development of during resistance among the general population.

\section{ACKNOWLEDGEMENTS}

The authors would like to acknowledge all mothers and interns who participated in the research.

\section{REFERENCE}

1. Corrêa Junior M, Passini Júnior R. Selective Episiotomy: Indications, Techinique, and Association with Severe Perineal Lacerations. Rev Bras Ginecol e Obs / RBGO Gynecol Obstet. 2016;38(06):301-7.

2. Edmonds DK, Dewhurst J. Dewhurst's textbook of obstetrics \&amp; gynaecology [Internet]. Blackwell Pub; 2007 [cited 2019 Oct 14]. 717 p.

3. Watanabe-Galloway S, Zhang W. Analysis of U.S. Trends in Discharges From General Hospitals for Episodes of Serious Mental Illness, 1995-2002. Psychiatr Serv [Internet]. 2007;58(4):496-502.

4. Standards for improving quality of maternal and newborn care in health facilities. [cited 2019 Oct 15].

5. Crann SE, Cunningham S, Albert A, Money DM, Doherty KCO. Vaginal health and hygiene practices and product use in Canada: a national cross- sectional survey. 2018;1-8.

6. The Management of Third- and Fourth-Degree Perineal Tears. [cited 2019 Oct 15].

7. Declercq ED, Sakala C, Corry MP, Applebaum 5 RP. Listening to Mothers: Report of the first National US Survey of Women's Childbearing Experience New York. Maternity Centre Association, 2002. [cited 2019 Oct 
15].A

8. Jiang H, Qian X, Carroli G, Garner P. Selective versus routine use of episiotomy for vaginal birth. Cochrane Database Syst Rev [Internet]. 2017 Feb 8 [cited 2019 Oct 22];

9. Ronald Lee Nichols. Preventing Surgical Site Infections: A Surgeon's Perspective. Emerg Infect Dis. 2001;7(2):220-4.

10. Weber AM, Meyn L. Episiotomy use in the United States, 1979-1997. Obstet Gynecol. 2002;100(6):117782.

11. Erku DA, Mekuria AB, Belachew SA. Inappropriate use of antibiotics among communities of Gondar town, Ethiopia: a threat to the development of antimicrobial resistance. Antimicrob Resist Infect Control. 2017;6(1):112.

12. Shankar P R, Upadhyay D K, Subish P, Bhandari R B DB. Drug utilisation among older inpatients in a teaching hospital in Western Nepal. Singapore Med J. 2010;51(1):28-34.

13. Carlet J, Jarlier V, Harbarth S, Voss A, Goossens H, Pittet D, et al. Ready for a world without antibiotics? The Pensières Antibiotic Resistance Call to Action. Antimicrob Resist Infect Control. Antimicrob Resist Infect Control. 2012;1(1):11.

14. Scottish Intercollegiate Guidelines Network. SIGN 50 A guideline developer's handbook. 2014.

15. Rodrigues SB, Néné $M$. The place of episiotomy in history: A sore review. J Nurs Educ Pract. 2018;9(4):122.

16. Bilquees Parveen, Gulfi shan Haq AS. Routine versus selective episiotomy in primigravidae. Pak J Surg. 2012;28(4):285-90.

17. Bowler PG, Duerden BI, Armstrong DG. Wound microbiology and associated approaches to wound management. Clin Microbiol Rev. 2001;14(2):244-69.

18. Leaper DJ. Prophylactic and therapeutic role of antibiotics in wound care. Am J Surg. 1994;167(1):S1520.

19. Zelenitsky SA, Ariano RE, Harding GKM, Silverman RE. Antibiotic pharmacodynamics in surgical prophylaxis: an association between intraoperative antibiotic concentrations and efficacy. Antimicrob Agents Chemother. 2002;46(9):3026-30.

20. Whitelaw AC. Role of infection control in combating antibiotic resistance. South African Med J. 2015;105(5):421.

21. Dindo D, Demartines N, Clavien PA. Classification of surgical complications: A new proposal with evaluation in a cohort of 6336 patients and results of a survey. Annals of Surgery. 2004;240(3):205-13.

Source of Support: Nil; Conflict of Interest: None

Submitted: 20-11-2019; Accepted: 02-12-2019; Published online: 25-12-2019 